УДК 622.243.1

ОСОБЕННОСТИ ТЕХНИКИ И ТЕХНОЛОГИИ БУРЕНИЯ

СКВАЖИН НА МЕСТОРОЖДЕНИИ «БЕЛЫЙ ТИГР»

(РЕСПУБЛИКА ВЬЕТНАМ)

\title{
FEATURES OF DRILLING TECHNIQUE AND TECHNOLOGY AT OIL FIELD «WHITE TIGER» (REPUBLIC OF VIETNAM)
}

\author{
Левинсон Л.М., Буй Ань Ту
}

Уфимский государственный нефтяной технический университет, г. Уфа, Российская Федерация

\section{L.M. Levinson, Bui Anh Tu}

Ufa State Petroleum Technological University, Ufa, Russian Federation e-mail: fernandotorresbui@gmail.com

Аннотация. В данной статье приведены технологические особенности бурения морских скважин на шельфе месторождения «Белый Тигр» (Республика Вьетнам). Месторождение «Белый Тигр» оценивается как одна из самых крупных площадок в Северо-Западном районе Тихого океана с дебитом до тыс. т. нефти в сутки. Нефть и газ обнаружены в миоценовом и олигоценовом стратиграфических отделах на глубине больше 2500 м.

Приводятся расположение скважин на буровых платформах и очерёдность их бурения и освоения. Наряду с этим рассматривается сравнение с кустовым бурением на суше. Во Вьетнаме широко применяют бурение боковых стволов с целью увеличения добычи и снижения стоимости строения скважин. Компанией «Вьетсовпетро» предложены технологические мероприятия для предупреждения встречи и пересечения стволов наклонно-направленных скважин. 
Особенностью конструкции морских скважин является задавливание водоотделяющей колонны диаметром больше 700 мм, что приводит к изменению технологии и техники бурения. Кондуктор диаметром 508 мм обычно совпадает с вертикальным участком длиной несколько сот метров, проводят жесткую компоновку низа бурильнных труб. Профили скважин многообразные, глубина до 4000 м со смещением забоя до 2000 м. Широко применяются современные технологии, особенно роторные управляемые системы зарубежных компаний, которые являются наиболее эффективным способом для углубления сложнопрофильных скважин.

Изложено применение морской воды в качестве буровой промывочной жидкости, что соответствует основным требованиям и экономичности.

Abstract. This article shows specificities of offshore drilling technology in White Tiger (Bach Ho) oil field in Vietnam. White Tiger is known as one of the most major oil fields in North-West area of the Pacific with production rate thousands of tons by day. Oil and gas is in the Miocene and Oligocene at depth of more than $2500 \mathrm{~m}$.

The authors not only give information about location of wells and their drill queue but also compare their characters with onshore group drilling. Open hole side track is a popular method to increase extraction and reduce the cost of well construction. In this article the anticollision solutions of Vietsovpetro Company are presented.

A feature of offshore wells structure is riser with a diameter greater than $700 \mathrm{~mm}$, which leads to a change in drilling technology and techniques. A conductor with a diameter of $508 \mathrm{~mm}$, which usually coincides with the several hundred meters long vertical section, is carried out by the hard bottom hole assembly. Well profiles are multiform with depth up to $4000 \mathrm{~m}$ and bottomhole offset up to $2000 \mathrm{~m}$. Modern technologies are widely used, especially rotary steerable systems of foreign companies, which are the most effective way to make difficult-profile wells. 
The use of sea water as drilling mud is introduced. It satisfies the basic requirements and cuts down drill expenditure.

Ключевые слова: Белый Тигр, буровая морская платформа, самоподъемная плавучая буровая установка, роторные управляемые системы, Вьетсовпетро, глубина моря, технология бурения, профиль скважины, водоотделяющая колонна, предупреждение пересечения стволов, кустовое бурение.

Key words: White Tiger (Bach Ho) oil field, offshore drilling platform, jack-up rig, rotary steerable system, Vietsovpetro, depth of the sea, drilling technology, well profile, riser, anticollision, onshore group drilling.

На шельфе Вьетнама процесс бурения осуществляется на самоподъемных и стационарных платформах или блок-кондукторах (БК). БК представляет собой сооружение на морских месторождениях, служащее основанием оборудования для добычи нефти и газа, на котором размещены устья скважин как на кустовой площадке. В отличие от кустового способа строительства скважин на суше на БК устья скважин находятся не на одной линии (линия движения станка), а в шахматном порядке. Схема расположения устьев имеет форму прямоугольника (рисунок 1). Количество скважин на одной площадке может достигать 15-16. Расстояние между соседними скважинами составляет 3-4 м. Из-за большой разницы в азимутах вероятность пересечения стволов соседних скважин сведена к минимуму. Благодаря такому расположению обеспечивается возможность одновременного бурения, освоения, эксплуатации и ремонта скважин.

Если используемые компоновки и режимы бурения не гарантируют строгой вертикальности начального участка ствола скважины, то во избежание встречи стволов расстояние между устьями не должно быть менее: 


$$
a=2 h_{B} \cdot\left(\alpha_{B}+0,015\right),
$$

где $\quad h_{B}-$ длина вертикального участка;

$\alpha_{в}$ - максимальный зенитный угол, получаемый на данной площади при бурении вертикальных участков (радиан) [1].

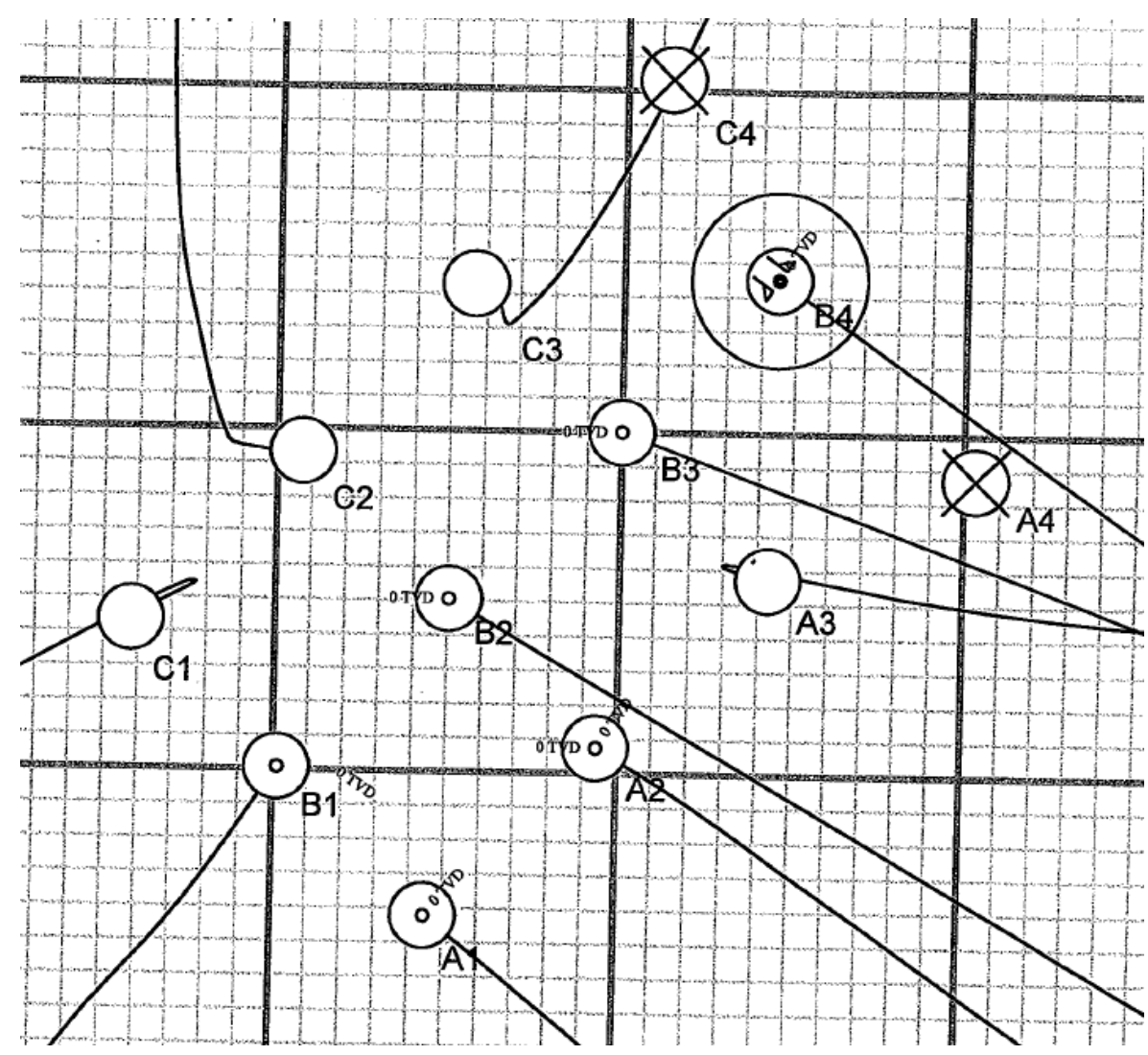

Рисунок 1. Схема расположения устьев скважин

Очередность бурения скважин на платформе и длины вертикальных участков определяются из следующих аргументов. Сначала бурят скважины, находящиеся на периферии схемы расположения, затем скважины, размещенные в центре сетки. Первыми бурят скважины с большими зенитными углами (большими отходами), а затем - с меньшими. Длина вертикального участка первой скважины должна быть минимальной. Для каждой очередной скважины на грани прямоугольника длина вертикального участка увеличивается по правилу - расстояние по вертикали между точками зарезки наклонных участков двух скважин должно быть не менее 30 м, если разница в азимутах забуривания менее 
10 о; 20 м - если разница азимутов $10-20$ о; 10 м - если азимуты отличаются более чем на 20 о [1].

СП «Вьетсовпетро» осуществляет следующие мероприятия по предупреждению пересечения стволов скважин при бурении:

- при забуривании скважины с морских стационарных платформ, БК, на соседних ранее пробуренных скважинах должны быть установлены шумомеры согласно проекту;

- перед бурением опасных интервалов на устье скважины должно быть установлено противовыбросовое оборудование согласно проекту;

- при бурении должен быть обеспечен круглосуточный контроль за работой шумомеров. Оператор, осуществляющий контроль за работой шумомеров, должен постоянно находиться в технологическом помещении во время бурения опасных интервалов;

- при бурении опасных участков параметры бурения должны контролироваться станцией контроля бурения - Геосервис.

С целью увеличения охвата пласта осуществляется бурение боковых стволов для получения дополнительной добычи. В одной скважине можно вырезать через окна 2-3 ответвления, это делает ее многозабойной, нижняя часть основного ствола которой имеет два и более горизонтальных, пологонаклонных или волнообразных стволов.

Метод возвращения к старым скважинам обладает рядом преимуществ:

- уменьшение числа скважин на месторождении, эффективная разработка мелких месторождений, помимо этого экономия средств в сравнении с бурением новых скважин;

- снижение стоимости строительства горизонтальных скважин, которые по производительности превосходят вертикальные скважины в 3-4 раза и дают значительный прирост извлекаемых запасов за счет охвата ранее недренированных участков пласта;

- возможность отбора углеводородов из коллекторов, ранее не охваченных разработкой [1]. 
В особых случаях бурят дополнительные скважины (сгущение сетки разработки), они размещены вне схемы с целью использования площади и оптимизации дебита. Таким образом, можно разместить на одном БК количество скважин до 20. Чем больше скважин в кусте, тем меньше стоимость строительства кустовой площадки и коммуникаций, приходящихся на одну скважину.

В настоящее время широко применяются и отвечают практически всем геолого-техническим условиям и технологическим требованиям бурения и эксплуатации профили скважин всех типов. Наиболее часто встречаются скважины J- и S-образного профиля с тремя или четырьмя интервалами, скважины с большим зенитным углом, скважины с горизонтальным участком, пространственные профили скважин.

Анализ приведенных типов профилей показывает, что все они имеют первый вертикальный участок, который нужен для создания минимально необходимой нагрузки на долото. Особенность профиля скважин на месторождении «Белый Тигр» заключается в том, что длина вертикального участка не должна быть менее 130-150 м при глубине Южно-Китайского моря 45-55 м и высоты поднятия буровой платформы над уровнем моря на 40-50 м. С другой стороны, длина вертикального участка не должна превышать 400-450 м с целью исключения вероятности встречи и пересечения стволов. Вторым всегда является участок набора величины зенитного угла. Практика показывает, что на участке набора зенитного угла интенсивность искривления не должна превышать 1,5 град./10 м с целью снижения износа насосных штанг и насосно-компрессорных труб, улучшения проходимости обсадных труб и компоновок бурильной колонны по стволу скважины. В некоторых регионах площади «Белый Тигр» по тем же причинам предлагают ограничение максимального зенитного угла ствола скважины в интервале установки глубиннонасосного оборудования величиной $25^{\circ}-30^{\circ}$, однако удовлетворительная 
эксплуатация электропогружных и штанговых насосов обеспечивается при зенитных углах 20-25 о [1, 2].

На месторождении «Белый Тигр» пробурили скважины с отходами практически до 2000 м. Большинство пологих скважин имеет длину ствола L много больше вертикальной глубины H, горизонтальный участок которых может удлиниться до 1500 м и идет по середине продуктивного пласта. Такие скважины, как правило, проводят роторным способом с применением роторных управляемых систем (РУС). Однако бурение добывающих скважин, предназначенных для эксплуатации залежи нефти фундамента (стратиграфического подразделения среднего олигоцена), имеющих глубину до 4000 м и короткий горизонтальный участок, осуществляется комбинацией способов бурения: с использованием РУС до кровли продуктивного пласта и применением забойного винтового двигателя для открытого горизонтального участка.

В последние годы в СП «Вьетсовпетро» строят скважины более сложного профиля, в том числе горизонтальные со смещением забоя до 1500 м, пространственные скважины с изменением азимута до 90 о и даже волнообразные профили скважин, имеющие несколько изгибающих участков. Проектирование таких скважин выполняется с помощью специальных компьютерных программ, например «Drilling Office», «Landmark Wellplan» и т.п., причем учитывается неоднородность продуктивного пласта, его толщина, литология, твердость и устойчивость пород, угол падения или восстания пласта, т.е. геологические факторы. В настоящее время актуальной задачей бурения на шельфе во Вьетнаме является поиск и эксплуатация нефти и газа на глубоководной структуре, на которой продуктивный пласт залегает на большой глубине (больше 4000 м) и характеризуется неоднородной структурой.

Основным критерием выбора типа буровых растворов для бурения морской скважины является их способность обеспечивать строительство высококачественных и рентабельных скважин, в том числе сложных 
конструкций с минимальным негативным воздействием на окружающую природную среду и фильтрационные свойства продуктивных пластов. Типы и параметры буровых растворов для строительства проектируемой скважины выбраны с учетом минералогического состава и свойств горных пород, слагающих разрез, а также анализа практического опыта бурения на тех структурах.

Пример параметров бурового раствора по интервалам бурения представлен в таблице 1.

Морская вода нашла широкое применение для промывки участка кондуктора (первые 200-400м), благодаря своей легкодоступности и дешевизне. Морская вода, как и безглинистые пресные растворы и естественные суспензии, состоящая из растворенных солей натрия и калия, обладает высоким ингибирующим свойством к набуханию, малой вязкостью и высокой охлаждающей способностью. К преимуществам морской воды относятся повышение показателей работы долот, достаточно высокий уровень очистки забоя и ствола скважины и недефицитность [3].

Все виды буровых промывочных жидкостей практически применяются для бурения нижних интервалов (стратиграфическое подразделение миоцена и олигоцена), в том числе распространенными являются система калиевого лигносулфонатного раствора, ингибирующего раствора KCl-Glycol-AKK-CFL и алюминизированного раствора. Вскрытие продуктивного пласта в принципе проводится биополимерным безглинистым раствором, но в несложной стратиграфии можно использовать полимерный малоглинистый раствор за счет снижения потребности материалов. 
Таблица 1. Типы и параметры буровых растворов для бурения скважины 1608БК-16 на месторождении «Белый Тигр»

\begin{tabular}{|c|c|c|c|c|c|c|c|c|c|c|}
\hline \multirow{3}{*}{ Интервал } & \multirow{3}{*}{$\begin{array}{c}\text { Тип } \\
\text { бурового } \\
\text { раствора }\end{array}$} & \multicolumn{9}{|c|}{ Параметры бурового раствора } \\
\hline & & \multirow{2}{*}{ 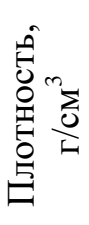 } & \multirow{2}{*}{ 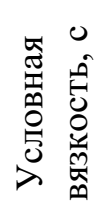 } & \multirow{2}{*}{ 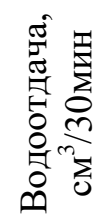 } & \multirow{2}{*}{ 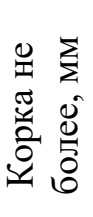 } & \multicolumn{2}{|c|}{$\begin{array}{l}\text { СНС, дПа } \\
\text { через мин }\end{array}$} & \multirow{2}{*}{$\begin{array}{c}\text { Плас. } \\
\text { вязкость, } \\
\text { мПа.с }\end{array}$} & \multirow{2}{*}{$\begin{array}{l}\text { ДНС, } \\
\text { дПа }\end{array}$} & \multirow{2}{*}{$\mathrm{pH}$} \\
\hline & & & & & & 1 & 10 & & & \\
\hline Кондуктор & $\begin{array}{c}\text { Морская } \\
\text { вода }\end{array}$ & - & - & - & - & - & - & - & - & - \\
\hline $\begin{array}{l}\text { Промежу- } \\
\text { точная } \\
\text { колонна }\end{array}$ & $\begin{array}{c}\text { Полимер } \\
\text { глинистый }\end{array}$ & 1,12 & $50-60$ & $6-8$ & 1,5 & $\begin{array}{l}15- \\
30\end{array}$ & $\begin{array}{c}25- \\
50\end{array}$ & $8-15$ & $\begin{array}{l}85- \\
105\end{array}$ & 9 \\
\hline \multirow{2}{*}{$\begin{array}{l}\text { Эксплуата- } \\
\text { ционная } \\
\text { колонна }\end{array}$} & $\begin{array}{c}\text { Лигно- } \\
\text { сульфонат- } \\
\text { ный }\end{array}$ & 1,14 & $50-60$ & $5-6$ & 1,5 & $\begin{array}{l}25- \\
75\end{array}$ & $\begin{array}{l}45- \\
90\end{array}$ & $8-20$ & $\begin{array}{l}85- \\
120\end{array}$ & 9 \\
\hline & $\begin{array}{c}\text { Ингиби- } \\
\text { рующий } \\
\text { алюмо- } \\
\text { калиевый }\end{array}$ & 1,22 & $50-60$ & $\begin{array}{l}3- \\
4,5\end{array}$ & 1,5 & $\begin{array}{l}40- \\
75\end{array}$ & $\begin{array}{l}75- \\
120\end{array}$ & $15-20$ & $75-95$ & 9 \\
\hline
\end{tabular}

Как видно из таблицы 1, условная вязкость поддерживается в течение 50-65 с, а показатель фильтрации в пределах 4-6 см³/30 мин и не должен превышать 4,5 см³/30мин при вскрытии продуктивного пласта. Значения показателей свойств буровых растворов по интервалам бурения скважины представлены в программе сервисного подрядчика DMS-WS.

Углубление скважины проводят различными типами компоновки низа бурильных колонн (КНБК), составляющие элементы которых зависят от цели бурения, конструкции и профиля скважины и также геологических факторов. Поскольку функцию направления выполняет водоотделяющая колонна (стояк или райзер) диаметром 711-762 мм глубиной 90-120 м, задавливающаяся в грунт, то проводка скважины начинается бурением под кондуктор диаметром 508 мм [4]. При этом для экономичности и повышения скорости бурения используется трехшарошечное долото $\varnothing 660,4$ мм первого класса со стальным вооружением для мягких пород (песок, глина), которое дорабатывает до глубины 400 м. Долото PDC 
применяется для бурении интервала эксплуатационной колонны с глубины 1000 м, в котором залегают горные породы средней твердости с низкой абразивностью.

Вертикальный участок, как правило, разбуривается роторным способом и жесткой компоновкой, обеспечивающей достаточную вертикальность ствола скважины [1]. КНБК состоит из 2-3 полноразмерных калибраторов и стабилизатора, утяжеленных труб (УБТ) длиной 28-37 м, жесткость которых не менее жесткости спускаемых обсадных колонн.

Отличительной особенностью бурения участков с изменением зенитного угла является все большее использование современных технологий с применением РУС для бурения протяженных интервалов под обсадную колонну $\mathrm{D}=245$ мм и $\mathrm{D}=178$ мм. Системы Rotary Steerable PDX5 900 и Autotrak 9 1/2 G3, применяемые в СП «Вьетсовпетро», это новое поколение бурового оборудования для более безопасного ведения работ. Они отличаются повышенной надежностью и высокой производительностью с возможностью большей проходки за долбление, оптимизацией траектории ствола при сокращении времени бурения и спуско-подъемных операций. Применяя принцип «рush the bits» и «point the bit» (асимметричное разрушение забоя и фрезерование стенки скважины), РУС улучшают качество ствола и, следовательно, его очистку, что особенно важно в горизонтальных скважинах. Основное преимущество РУС по сравнению с винтовыми забойными двигателями (ВЗД) и турбобурами - это возможность управлять искривлением скважин при вращении бурильной колонны, что снижает силы трения бурильной колонны о стенки скважины [1].

Следует отметить, что эффективность внедрения роторных управляемых систем зависит, прежде всего, от широкого комплекса используемого технологического оборудования, взаимосвязанного между собой.

Основные недостатки применения РУС: 
- высокая зарплата на аренду бригады зарубежной компании;

- потребность дополнительных компонентов, необходимых для работы, например, ВСРМ (модуль двунаправленной связи компании «Бейкер Хюзь»), MWD (телеметрическая система), вспомогательный фильтр и т.д.;

- высокая стоимость комплекса бурильных инструментов и сопровождаемых средств;

- высокая квалификация буровой бригады.

В некоторых случаях, когда нет сложностей в управлении траекторией скважины, в качестве отклонителя используется ВЗД с регулируемым углом искривления между секциями. Преимущества над турбобуром - ВЗД имеет корпус короче и частоту вращения меньше, вследствие этого обеспечивается более высокий момент на долоте. Ориентируемые компоновки применяют для набора или спада зенитного угла и для исправления параметров кривизны, если фактический профиль скважины значительно отличается от проектного. Их основными элементами являются ВЗД над долотом, лопастный калибратор и центратор над двигателем, телеметрическая система и диамагнитная УБТ.

Чаще всего телесистема имеет гидравлический канал связи, обладающий возможностью свободного вращения бурильной колонны и простотой применения (телеметрическая сборка в диамагнитной трубе включается в состав КНБК над забойным двигателем и вместе с бурильной колонной спускается в забой, управление передачей данных осуществляется кратковременным выключением и включением буровых насосов). Система с положительным импульсом нашла широкое применение благодаря простоте конструкции и мощным легко регистрируемым сигналам, однако она чувствительна к наполнителям и производительности насосов [5]. Система с непрерывным импульсом, которая предлагается компанией «Шлюмберже», обеспечивает большую скорость передачи информации, но требует высокого качества бурового 
раствора. С целью исключения шума и помех, вызывающих угасание сигнала с забоя на поверхность, рекомендуется применить компенсатор и установить два датчика давления с последующей обработкой данных на стояке. Следует признать, что оптимальный выбор телесистемы зависит от конкретных условий эксплуатации.

Как отмечено выше, специфичность конструкции морских скважин во Вьетнаме - это наличие райзера диаметром больше 700 мм. Водоотделяющие трубы соединяются с помощью электродуговой сварки. Сварные соединения повышают герметичность обсадных труб и их прочность особенно в случае относительного колебания буровой платформы под действием волны [4, 6]. Обсадные трубы, обычно имеющие трапецеидальную резьбу VAMTOP с уплотнением типа «металл по металлу» на ниппельном конце, спускаются при креплении скважины с максимальной скоростью $0,6-0,8$ м/с для исключения возможности гидроразрыва пласта. В необсаженном стволе до кровли продуктивного пласта (при его отсутствии - до 200 м выше забоя) скорость спуска колонны принята равной 0,3 м/с, а в интервалах продуктивного пласта скорость спуска не превышает 0,25 м/с.

Для исключения прихвата при проведении промежуточной промывки в открытом стволе нельзя оставлять обсадную колонну без движения более 3-х мин. Обсадные колонны цементируются прямым одноступенчатым способом. Такой способ обладает простотой применения, надежностью контроля процесса и соответствует техническим условиям на многих предприятиях Вьетнама. Особенностью характеристик тампонажных жидкостей является низкая плотность цементного раствора. Плотность обычного цементного раствора составляет 1,72 г/см3, а облегченного раствора $1,52-1,57$ г/см3.

В большинстве случаев промежуточные колонны цементируются только облегченными цементными растворами, а хвостовик-фильтр остается не зацементированным. 


\section{Вывод}

Таким образом, технология бурения на море во Вьетнаме, как и во всем мире, отличается конструкцией скважин с подводным устьем, которая включает в себя направление (райзер) и кондуктор большим диаметром.

Особое внимание уделяется использованию естественной воды в качестве буровой жидкости для уменьшения затрат и применения РУС, которые оцениваются лучшим вариантом для управления искривлением скважин при вращении бурильной колонны.

\section{Список используемых источников}

1. Левинсон Л.М., Акбулатов Т.О., Хасанов Р.А., Левинсон М.Л. Строительство и навигация сложнопрофильных скважин: учеб. пособие. Уфа: УГНТУ, 2013. 157 с.

2. Акбулатов Т.О., Левинсон Л.М., Салихов Р.Г., Янгиров Ф.Н. Расчеты при бурении наклонных и горизонтальных скважин: учеб. пособие. Уфа: УГНТУ, 2005. 98 с.

3. Овчинников В.П., Агзамов Ф.А., Акбулатов Т.О. и др. Технология бурения нефтяных и газовых скважин: учебн. для студентов вузов: в 5 т. Тюмень: ТюмГНГУ, 2014. Т. 2: 560 с.

4. Овчинников В.П., Агзамов Ф.А., Акбулатов Т.О. и др. Технология бурения нефтяных и газовых скважин: учебн. для студентов вузов: в 5 т. Тюмень: ТюмГНГУ, 2014. Т. 3: 342 с.

5. Янгиров Ф.Н., Яхин А.Р., Матюшин В.П., Мухаметгалиев И.Д. Забойные телеметрические системы: учеб. пособие. Уфа: УГНТУ, 2017. $56 \mathrm{c}$.

6. Овчинников В.П., Агзамов Ф.А., Акбулатов Т.О. и др. Технология бурения нефтяных и газовых скважин: учебн. для студентов вузов: в 5 т. Тюмень: ТюмГНГУ, 2014. Т. 5: 322 с. 


\section{References}

1. Akbulatov T.O., Levinson L.M., Khasanov R.A., Levinson M.L. Stroitel'stvo $i$ navigatsiya slozhnoprofil'nykh skvazhin: ucheb. posobiye [Constructing and Navigation of Wells with Complicated Profile: Textbook for University Students]. Ufa, USPTU, 2013. 157 p. [in Russian].

2. Akbulatov T.O., Levinson L.M., Salikhov R.G., Yangirov F.N. Raschety pri burenii naklonnykh i gorizontal'nykh skvazhin: ucheb. posobiye [Directional Drilling Calculations: Textbook for University Students]. Ufa, USPTU, 2005. 98 p. [in Russian].

3. Ovchinnikov V.P., Agzamov F.A., Akbulatov T.O. e.a. Tekhnologiya bureniya neftyanykh i gazovykh skvazhin: ucheb. dlya studentov vuzov: $v 5 t$. [Drilling Technology for Oil and Gas: Textbook for University Students: in 5 Vol.]. Tyumen, Tyumen State Oil and Gas University, 2014. Vol. 2: 560 p. [in Russian].

4. Ovchinnikov V.P., Agzamov F.A., Akbulatov T.O. e.a. Tekhnologiya bureniya neftyanykh i gazovykh skvazhin: ucheb. dlya studentov vuzov: $v 5 t$. [Drilling Technology for Oil and Gas: Textbook for University Students: in 5 Vol.]. Tyumen, Tyumen State Oil and Gas University, 2014. Vol. 5: 322 p. [in Russian].

5. Yangirov F.N., Yakhin A.R., Matyushin V.P., Mukhametgaliev I.D. Zaboynyye telemetricheskiye sistemy: ucheb. posobiye [Downhole Telemetry System: Textbook for University Students]. Ufa, USPTU, 2017. 56 p. [in Russian].

6. Ovchinnikov V.P., Agzamov F.A., Akbulatov T.O. e.a. Tekhnologiya bureniya neftyanykh i gazovykh skvazhin: ucheb. dlya studentov vuzov: $v 5 t$. [Drilling Technology for Oil and Gas: Textbook for University Students: in 5 Vol.]. Tyumen, Tyumen State Oil and Gas University, 2014. Vol. 3: 342 p. [in Russian]. 


\section{Сведения об авторах}

\section{About the authors}

Левинсон Л.М., канд. техн. наук, профессор кафедры «Бурение нефтяных и газовых скважин», ФГБОУ ВО «УГНТУ», г. Уфа, Российская Федерация

L.M. Levinson, Candidate of Engineering Sciences, Professor of Oil and Gas Wells Drilling Department, FSBEI HE «USPTU», Ufa, Russian Federation

Буй Ань Ту, студент кафедры «Бурение нефтяных и газовых скважин», ФГБОУ ВО «УГНТУ», г. Уфа, Российская Федерация

Bui Anh Tu, Student Engineering Sciences, Professor of Oil and Gas Wells Drilling Department, FSBEI HE «USPTU», Ufa, Russian Federation e-mail: fernandotorresbui@gmail.com 